\title{
Protective Effects of Morus nigra and Its Phytochemicals against Hepatotoxicity: A Review of Preclinical Studies
}

\author{
Ahmad Ghorbani ${ }^{a, b}$ Sara Hooshmand ${ }^{a, b}$ \\ aPharmacological Research Center of Medicinal Plants, Mashhad University of Medical Sciences, Mashhad, Iran; \\ ${ }^{b}$ Department of Pharmacology, Faculty of Medicine, Mashhad University of Medical Sciences, Mashhad, Iran
}

\section{Keywords}

Anthocyanins · Black mulberry · Cyanidin · Liver · Morus nigra

\begin{abstract}
Background: Our liver has a variety of vital functions including removing poisons, storing energy, immunological roles, and secretory and excretory functions. It may face some kinds of diseases caused by viruses, hepatotoxic chemicals, drugs, alcohol, and inherited disorders. Oxidative stress and inflammation are in the core of mechanisms of liver damages induced by viruses or chemical agents. Summary: Morus nigra (M. nigra), generally known as black mulberry, exhibited wide-spectrum pharmacological effects including antidiabetic, antinociceptive, anticancer, and hepatoprotective activities. Different parts of this plant particularly the fruit and leaf have shown beneficial effects on hepatocytes in cell culture and animal models of liver damages induced by chemicals (e.g., CCl4), drugs (e.g., paracetamol), diet (e.g., high fat), diabetes, etc. The beneficial effects of $M$. nigra on the liver are attributed to the presence of considerable amounts of phenolic compounds such as anthocyanins, flavonols, and phenolic acids. The present review is aimed to focus on the hepatoprotective activities of $M$. nigra and its
\end{abstract}

phytochemicals and the mechanisms responsible for these activities. Key Messages: The evidence reviewed in this study can help design clinical trials on $M$. nigra in patients with liver disorders and develop a hepatoprotective herbal medicine.

(c) 2021 S. Karger AG, Basel

\section{Introduction}

The liver, as the largest organ inside our body, has a variety of vital functions including removing poisons, storing energy, immunological roles, and secretory and excretory functions [1]. It may face some kinds of diseases caused by viruses (e.g., hepatitis A, B, and C), hepatotoxic chemicals, drugs, too much alcohol (e.g., fatty liver disease and cirrhosis), and inherited disorders (e.g., Wilson disease and hemochromatosis). Although there are some symptoms like yellowing of the skin and eyes as well as swelling of the abdomen and legs, sometimes no symptoms are observed in the patients [2].

In the last decade, considerable progress has been made in our understanding of the pathophysiology of liver disorders. Oxidative stress and inflammation are in the 
Main phenolic compounds:

\section{Morus nigra}

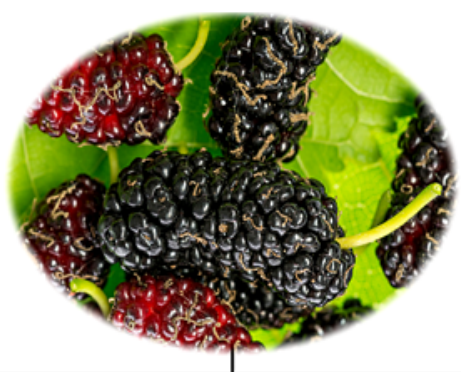

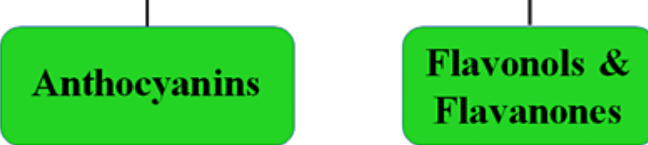

Example:
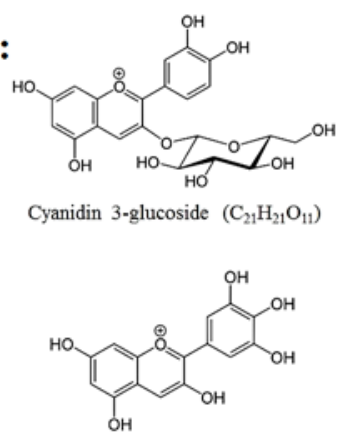

Delphinidin $\left(\mathrm{C}_{15} \mathrm{H}_{11} \mathrm{O}_{7}\right)$

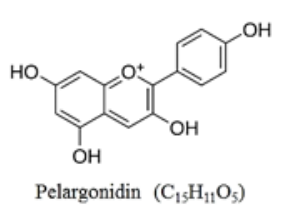

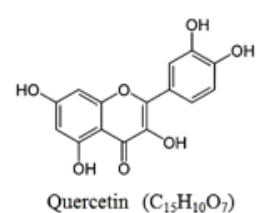

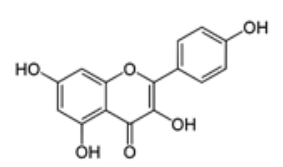

Kaempferol $\left(\mathrm{C}_{15} \mathrm{H}_{10} \mathrm{O}_{6}\right)$

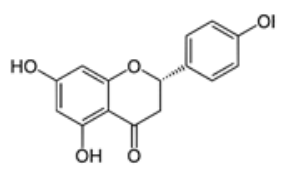

Naringenin $\left(\mathrm{C}_{15} \mathrm{H}_{12} \mathrm{O}_{5}\right)$

\section{Phenolic acids}

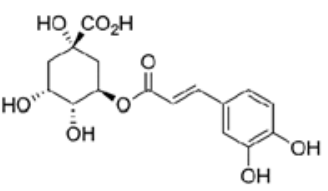

Chlorogenic acid $\left(\mathrm{C}_{10} \mathrm{H}_{18} \mathrm{O}_{9}\right)$<smiles>O=C(O)c1cc(O)c(O)c(O)c1</smiles>

Gallic acid $\left(\mathrm{C}_{7} \mathrm{H}_{6} \mathrm{O}_{5}\right)$<smiles>O=C(O)/C=C/c1ccc(O)c(O)c1</smiles>

Caffeic acid $\left(\mathrm{C}_{9} \mathrm{H}_{8} \mathrm{O}_{4}\right)$

\section{Cinnamic acid derivatives}<smiles>O=C(O)/C=C/c1ccc(O)cc1</smiles>

P-Coumaric acid $\left(\mathrm{C}_{9} \mathrm{H}_{8} \mathrm{O}_{3}\right)$<smiles>COc1cc(/C=C/C(=O)O)ccc1O</smiles>

Ferulic acid $\left(\mathrm{C}_{10} \mathrm{H}_{10} \mathrm{O}_{4}\right)$<smiles>COc1cc(/C=C/C(=O)O)cc(OC)c1O</smiles>

Sinapic acid $\left(\mathrm{C}_{11} \mathrm{H}_{12} \mathrm{O}_{5}\right)$

Fig. 1. The main phenolic compounds found in Morus nigra.

core of mechanisms of liver damages induced by viruses or chemical agents $[3,4]$. Antioxidant and anti-inflammatory effects of medicinal plants and their phytochemicals have been well documented $[5,6]$. Therefore, finding effective and safe natural hepatoprotective agents is one of the future directions.

Berries, particularly the popular ones such as blueberry, strawberry, raspberry, and blackberry, are among the best plants with medicinal value due to the presence of a wide range of bioactive phenolic components [7]. These plants exhibited wide-spectrum biological effects including antidiabetic, anticancer, antiaging, neuroprotective, and lipid metabolism regulatory activities [7-10]. Blackberry (black mulberry) with the scientific name of Morus nigra (M. nigra) grows in different parts of the world par- ticularly in Southwestern Asia and Europe. The fruits and leaves of this plant have shown remarkable antioxidant, anti-inflammatory, and antiviral activities [11-14]. The present review is aimed to focus on the hepatoprotective effects of M. nigra and its phytochemicals.

\section{Phytochemical Profile of $M$. nigra}

There are about 4,000 different phytochemicals found to be responsible for taste, color, and other related functions of plants [15]. Two main forms of plant-derived phytochemicals include primary types (e.g., amino acids, carbohydrate, proteins, and chlorophyll) and secondary phytochemicals (e.g., flavonoids, terpenoids, al- 
kaloids, saponins, anthraquinones, and volatile oils) [16]. The main phytochemical compounds found in $M$. nigra are shown in Figure 1. The leaf and fruit contain considerable amounts of phenolic compounds such as anthocyanins (e.g., cyanidin-3-glucoside, cyanidin3-rutinoside, and pelargonidin), flavonols (e.g., quercetin, rutin, and kaempferol), flavanones (e.g., naringenin), and phenolic acids (e.g., chlorogenic acid, gallic acid, and caffeic acid).

It has been well documented that phytochemical compositions of mulberries, like other plants, are influenced by the type of species, genetic differences, and geographical and environmental conditions. For example, $M$. nigra has higher concentrations of flavonoids compared to Morus alba (M. alba), the white mulberry [17-21]. Also, the levels of chlorogenic acid, syringic acid, O-coumaric acid, and vanillic acid were shown to be higher than those of $M$. alba and Morus rubra (red mulberry) [17]. The differences in the level of flavonoids justify the greater antioxidant and anticancer activities of $M$. nigra compared to $M$. alba and Morus rubra [17, 22, 23]. Also, a comparison of polyphenol composition and antioxidant activity of fresh $M$. nigra with different mulberry products (dried mulberry, mulberry wine, molasses, ice cream, juice, jam, and syrup) showed that fresh M. nigra has higher contents of total anthocyanins, phenolics, flavonoids, and antioxidant capacity [24]. For example, the content of anthocyanins in juice prepared by centrifugation, jam, jelly, juice prepared by thermal processing, syrup, canned fruit, and wine is approximately 106, $94,90,74,47,24$, and $21 \mathrm{mg} / \mathrm{dm}^{3}$, respectively [25]. It is well known that the phytochemical profile reported for a given plant depends on the type of the extraction method used for the study. A comparative study on 3 different extracts (infusion, decoction, and methanolic) of $M$. nigra showed more antioxidant phenolic compounds for the infusion extract compared to the 2 other forms [26]. Evaluating the profile of the phenolic compounds of M. nigra fruit before and after fermentation showed that the largest level of flavonoids is extracted from fresh fruits than from fermented fruits [27]. Also, the acetonic and methanolic extracts of $M$. nigra and $M$. alba fruits were analyzed for their phenolic compounds, and results showed that acetonic and methanolic extracts of $M$. nigra have the highest contents of total phenolics (173 mg/g and $164 \mathrm{mg} / \mathrm{g}$, respectively) [28]. Finally, genotypes strongly influence the chemical content and antioxidant capacity of $M$. nigra [23, 29]. Comparing the levels of organic acids, sugars, vitamin $\mathrm{C}$, and phenolic compounds in 3 genotypes of this plant showed that there is a significant difference between the genotypes regarding the amounts of these compounds [23].

Hepatoprotective Effects of Morus nigra and Its Phytochemicals

\section{Pharmacokinetics and Biodistribution of $M$. nigra Phytochemicals}

Contrary to in vitro conditions, the in vivo efficacy of phytochemicals mainly depends on their absorption, distribution, metabolism, and excretion. Pharmacokinetic studies have shown that flavonoids, the main phytochemical compounds found in M. nigra, can be absorbed from the gastrointestinal tract after oral administration [3033]. Measurement of the levels of 6 flavonols (rutin, isoquercitrin, astragalin, quercetin, kaempferol, and isorhamnetin) in rat plasma following a single oral dose $(1 \mathrm{~g} / \mathrm{kg})$ of mulberry leaves extract showed a maximum concentration ranging from $6.8 \pm 4.6$ to $132.5 \pm 73.3 \mathrm{ng} /$ $\mathrm{mL}$, the time to reach the maximum plasma concentration of $0.19 \pm 0.06$ to $0.30 \pm 0.13 \mathrm{~h}$, and half-life of elimination ranging from 0.87 to $1.19 \mathrm{~h}$ [30]. The flavonoid glycosides (isoquercitrin and rutin) are released as aglycone after being hydrolyzed in the intestinal tract by bacteria [31]. Following absorption, flavonoids undergo first-pass phase II metabolism in the epithelial cells of the small intestine and the liver. The predominant forms of metabolites present in plasma are those conjugated with methyl, glucuronate, and sulfate groups [32]. Finally, they are excreted through the bile and the kidney [34]. A biodistribution study of ${ }^{125} \mathrm{I}$-labeled rutin and ${ }^{123}$ I-labeled hesperetin in mice showed that in the first hour after oral administration, these flavonoids were found in the stomach and small intestines. Then, the observed radioactivity of the upper gastrointestinal tract was decreased while that of the large intestine displayed its maximum uptake after 3-4 h of administration. The labeled rutin and hesperetin were detected in different organs including the liver, lung, kidneys, heart, and spleen within 1-24 h [33, 34]. In addition to the animal studies described above, several clinical studies have addressed the pharmacokinetics of flavonoids in healthy volunteers. The results show considerable differences among the different types of flavonoids regarding absorption from the small intestine (ranging from 0 to $60 \%$ of the administrated dose) and half-life (ranging from 2 to $28 \mathrm{~h}$ ) [32].

Anthocyanins can be detected in the blood within minutes of oral consumption, suggesting that these compounds may be quickly absorbed from the stomach in addition to the small intestine. The extent of absorption of anthocyanins from the gastrointestinal tract is affected by their sugar moiety and acylated groups [35]. The exact mechanism behind the absorption of anthocyanins from the gastrointestinal tract is still uncertain. It has been suggested that bilitranslocase, an organic anion membrane carrier in the liver

Pharmacology 2021;106:233-243 235 


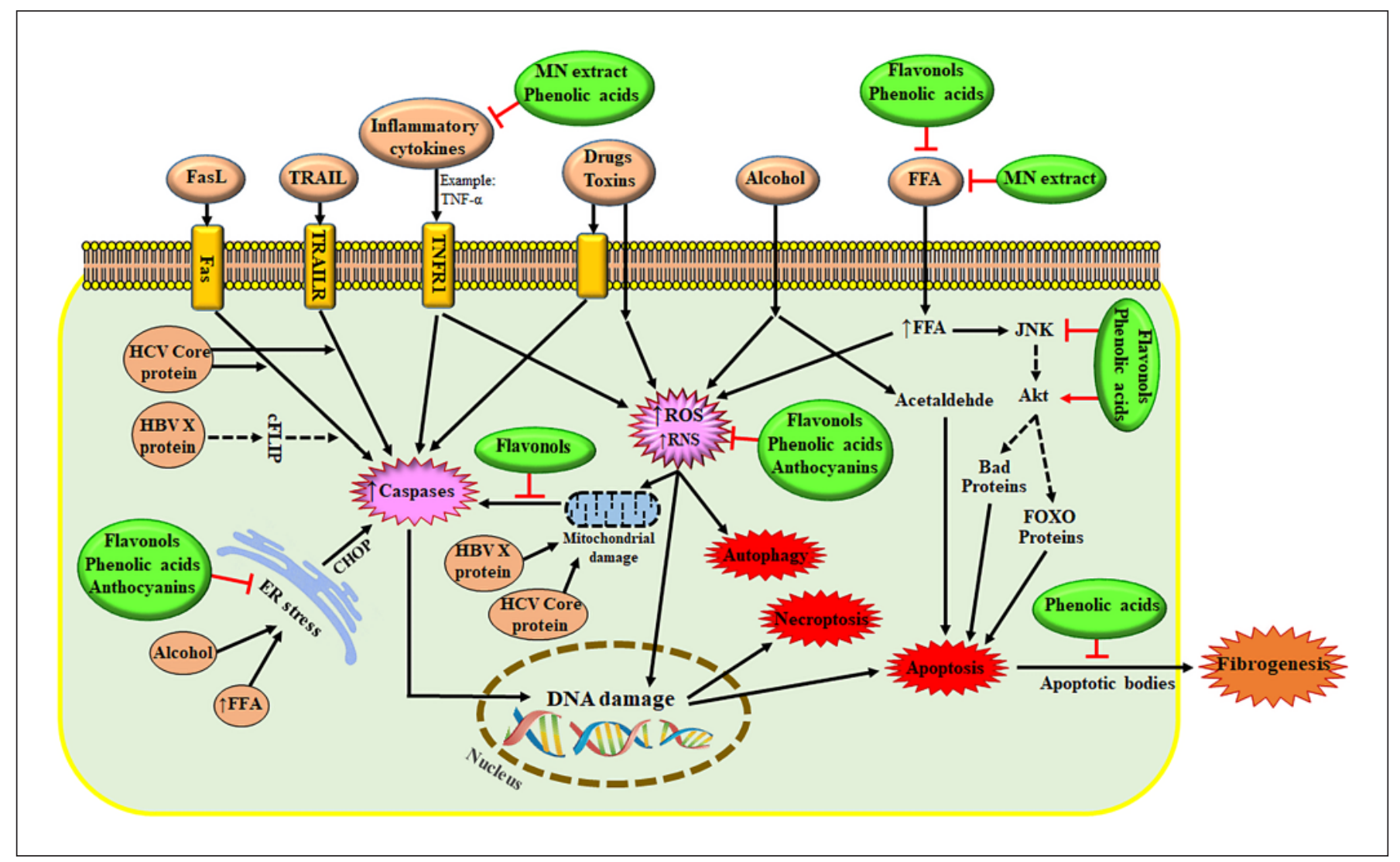

Fig. 2. Potential mechanisms of hepatoprotective effects of Morus nigra and its phytochemicals. Inhibitory effects are shown by red lines and dotted arrows. cFLIP, cellular FLICE inhibitory protein; ER, endoplasmic reticulum; FFA, free fatty acids; FasL, Fas ligand; FOXO, forkhead box class O; HBV, hepatitis B virus; HCV, hepatitis C virus; JNK, c-Jun N-terminal kinase; ROS/RNS, reactive oxygen/nitrogen species; TNFR1, tumor necrosis factor receptor-1; TNF- $\alpha$, tumor necrosis factor-alpha; TRAIL, TNF-related apoptosis-inducing ligand; TRAILR, TRAIL receptor.

and stomach, is involved in the bioavailability of anthocyanins [36]. Maximum plasma concentrations of total anthocyanins have been reported to be in the range of 1-100 $\mathrm{nmol} / \mathrm{L}$ in human studies [35]. Marques et al. [37] analyzed the plasma of healthy participants following consumption of blackberry purees and observed that some anthocyanins (cyanidin-3-glucoside and cyanidin-3-rutinoside) could be absorbed intact as native compounds and extensively metabolized into methylated, glucuronidated, and sulfated derivatives. The maximum plasma concentrations of cyanidin-3-glucoside and cyanidin-3-rutinoside were $47 \pm 8 \mathrm{ng} /$ $\mathrm{mL}\left(t_{\max }: 66 \pm 15 \mathrm{~min}\right)$ and $11 \pm 3 \mathrm{ng} / \mathrm{mL}\left(t_{\max }: 108 \pm 12\right.$ $\mathrm{min}$ ), respectively. Also, they reported that methyl-cyanidin-glucuronide and 3-methyl-cyanidin-3-glucoside were the main anthocyanin conjugates found in the plasma. Biotransformation of anthocyanins is done by enzymes located in the small intestine, liver, and kidney. Biodistribution studies in rats and pigs showed that anthocyanins could be found in different organs such as the liver, eye, and even the brain [35]. Excretion of anthocyanins in human urine peaked between 2 and $4 \mathrm{~h}$ following consumption of anthocyanin-rich juice [38].

\section{Molecular Mechanisms of Liver Damage}

The strategic anatomical location, specific blood flow, and unique role in metabolism and detoxification of poisons render the liver particularly vulnerable to damage by chemicals, viruses, and metabolic disorders [39]. The pathogenesis of chemical-induced hepatotoxicity is mainly initiated by conversion into reactive intermediate species, such as reactive oxygen species (ROS) and reactive nitrogen species (Fig. 2). When the antioxidant ca- 


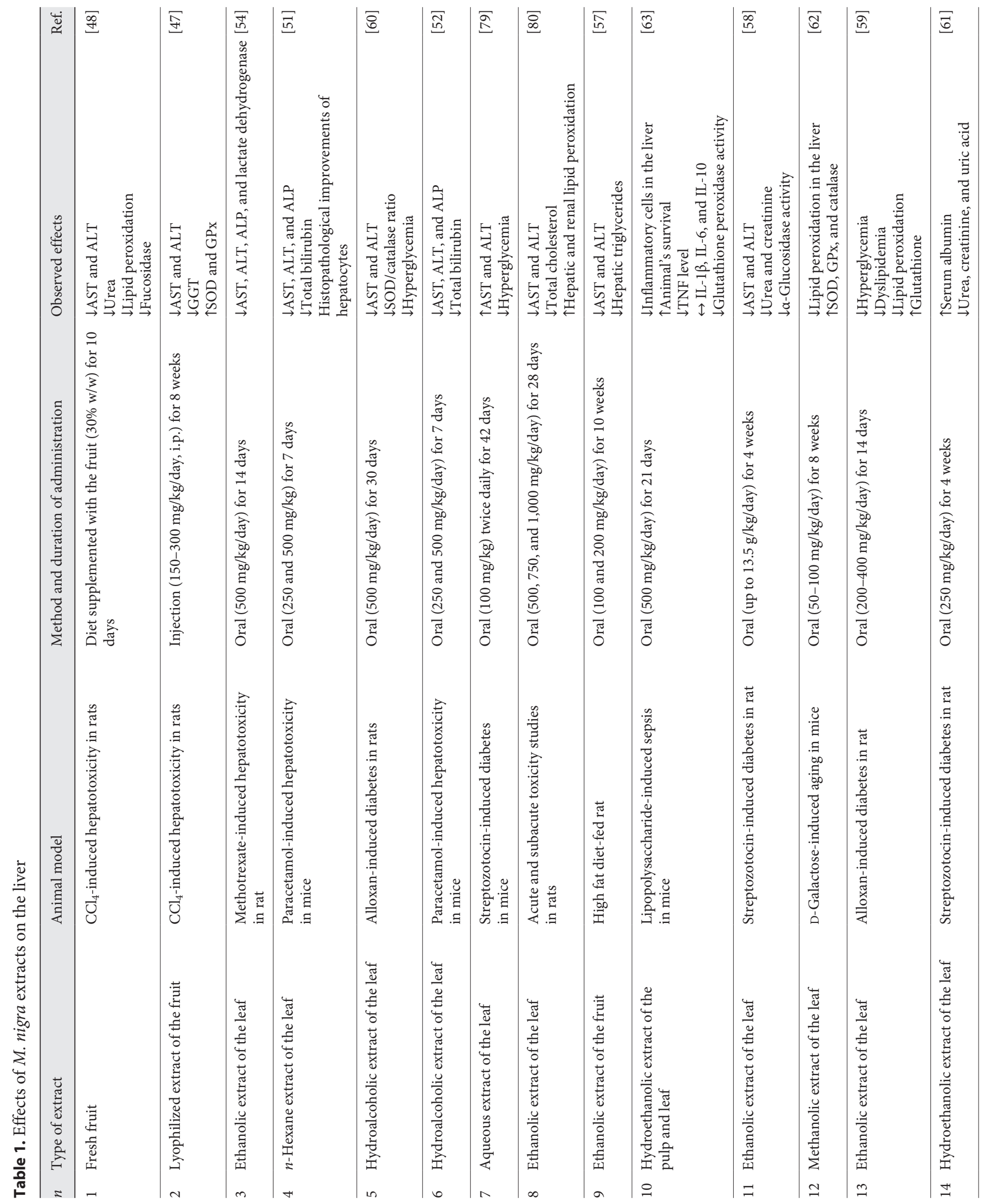


pacity of hepatocytes is overwhelmed by the excess generation of these species, oxidative stress occurs, which in turn deregulates cellular signaling pathways, alters the function and structure of biomolecules, and eventually promotes cell death through apoptosis, autophagy, necrosis, pyroptosis, and ferroptosis processes [39-42]. In the case of metabolic disorders, for example, nonalcoholic fatty liver disease (NAFLD), accumulation of fatty acids leads to the formation of lipotoxic species in hepatocytes that causes endoplasmic reticulum stress and excessive level of ROS and proinflammatory cytokines [43]. Inflammatory cytokines (e.g., TNF- $\alpha$, IL- $1 \beta$, and IL-18) can activate nuclear factor-kappa B and c-Jun N-terminal kinases pathways, which in turn upregulate the expression of these cytokines and therefore worsen inflammation, insulin resistance, and fibrosis. Activation of toll-like receptor family members in hepatitis can mediate steatosis, insulin resistance, and fibrosis in the liver $[43,44]$. In NAFLD, the increase in mitochondrial fatty acid oxidation and stimulation of the tricarboxylic acid cycle enhance the delivery of reducing equivalents to the electron transport chain. This excites the formation of superoxide as a precursor of ROS. Overproduction of ROS can damage mitochondria through degradation of mitochondrial structural integrity, interruption of electron transport chain, and permeabilization of the outer mitochondrial membrane. The antioxidant system can inhibit the vicious cycle of mitochondrial dysfunction. However, in hepatic disorders, parallel to the increased level of ROS, the reduced activity of the antioxidant system (e.g., glutathione, catalase, and superoxide dismutase [SOD]) can promote hepatocyte damage $[45,46]$.

\section{Effects of M. nigra Extracts on Hepatic Disorders}

Throughout human life, various hepatotoxic chemicals and drugs can enter the body and affect the liver. Different parts of $M$. nigra particularly the fruit and leaf showed a beneficial effect on hepatocytes in cell culture and animal models of liver damages induced by chemicals $\left(\mathrm{CCl}_{4}\right)$, drugs (paracetamol and methotrexate), diet (high fat), diabetes, etc. (Table 1).

The $\mathrm{CCl}_{4}$ has been shown to increase serum levels of liver enzymes, increase oxidative stress in hepatocytes, and induce pathological changes (increased numbers of Kupffer cells, vacuolization, and pericentral vein necrosis) in the liver of rats exposed to this compound [47]. Administration of the $M$. nigra extract to the $\mathrm{CCl}_{4}$-treated cells/animals could significantly increase the activities of 


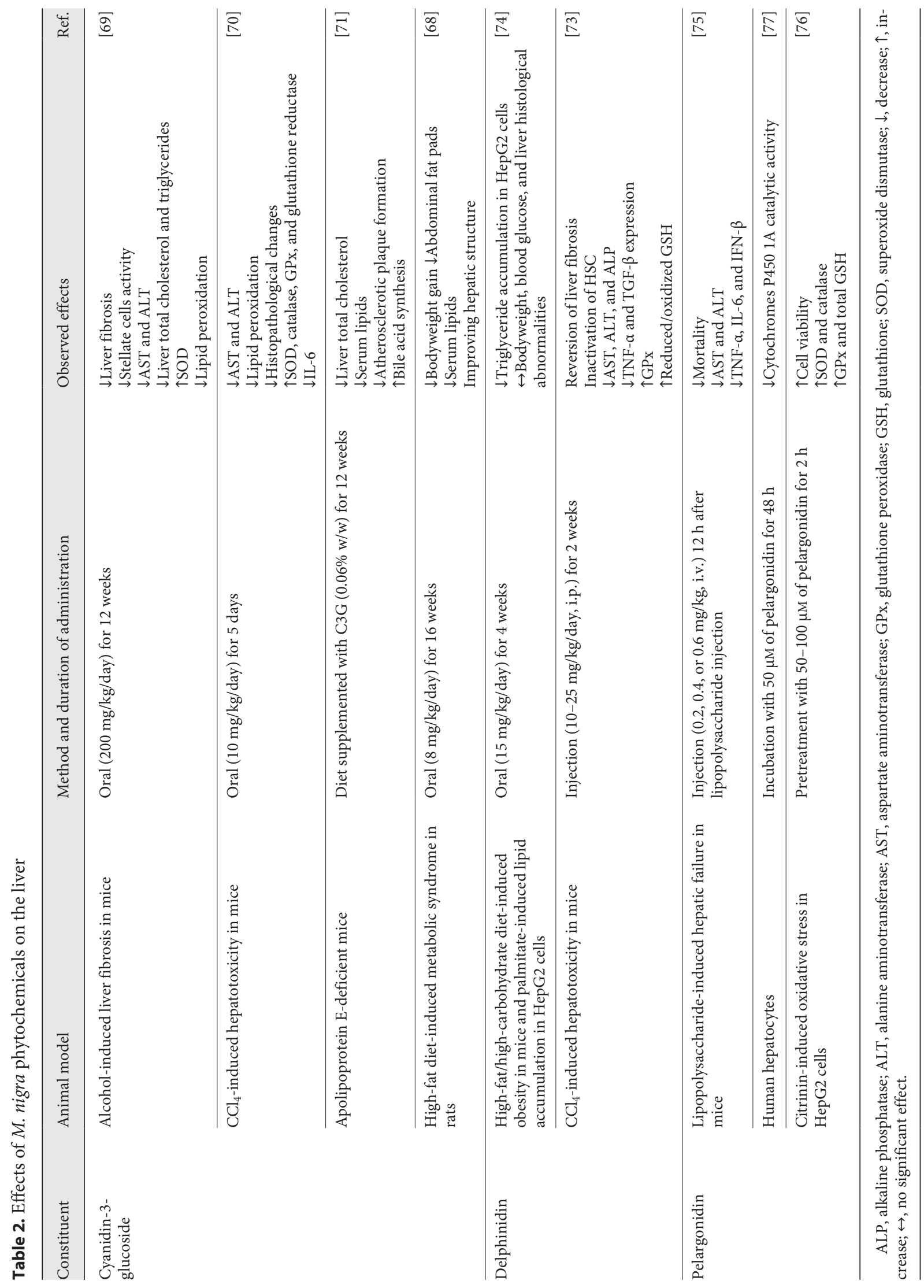


glutathione peroxidase and SOD [47-49]. The extract also decreased lipid peroxidation, prevented an increase in the levels of aspartate aminotransferase (AST) and gamma-glutamyl transferase, and improved the histological appearance of the liver $[47,48]$.

Overdose of paracetamol leads to accumulation of its metabolite $\mathrm{N}$-acetyl-p-benzoquinone imine, which covalently binds to proteins following depletion of glutathione in hepatocytes. The loss of glutathione increases the formation of ROS and nitrogen species and therefore leads to mitochondrial dysfunction, lipid peroxidation, and even acute hepatic necrosis $[50,51]$. Hepatoprotective activity of hydroalcoholic and n-hexane extracts of $M$. nigra leaves has been evaluated in paracetamol-intoxicated mice. The extracts at doses of $250 \mathrm{mg} / \mathrm{kg}$ and $500 \mathrm{mg} / \mathrm{kg}$ could reduce the levels of liver enzymes and total bilirubin and improve the histology of the liver. These beneficial effects of $M$. nigra were comparable to those of silymarin, a wellknown hepatoprotective phytochemical $[51,52]$.

Methotrexate, an immune system suppressant and chemotherapy agent, is another drug with potential hepatotoxic side effects (e.g., increased risk of elevated transaminase levels) [53]. The ethanolic extract of M. nigra leaves was shown to decrease the serum levels of AST, alanine aminotransferase (ALT), alkaline phosphatase, and lactate dehydrogenase in rats with methotrexate-induced liver injury [54].

In studies on high-fat diet-fed animals, $M$. nigra was shown to improve hepatic steatosis, decrease serum lipids (cholesterol, triglyceride, and low-density lipoprotein), decrease hepatic lipid peroxidation, enhance antioxidative enzyme activities, alleviate insulin resistance, and improve glucose homeostasis. These effects were associated with suppressed expression of glycerol kinase and fatty acid desaturase 2 and enhanced expression of adiponectin receptor- 2 and insulin-induced gene- 1 [55, 56]. In another study on high-fat diet-induced NAFLD in rats, administration of mulberry fruit extract for 10 weeks decreased the levels of serum ALT, AST, total cholesterol, triacylglycerol, and low-density lipoprotein cholesterol. Histological analysis demonstrated that the extract ameliorated lipid accumulation. This effect was associated with the downregulation of the expression of cholesterol homeostasis-related genes (ACC, FAS, SCD1 , and $S R E B P-1 c)$. Also, the extract inhibited hepatic ROS production and mitochondrial oxidative stress [57]. Therefore, the antihepatosteatosis activity of $M$. nigra might depend on its capability to inhibit the synthesis of fatty acids and cholesterol as well as its high antioxidant property.
The hepatoprotective effect of $M$. nigra has also been investigated in animal models of diabetes. In streptozotocin- and alloxan-induced diabetic rats, oral administration of the leaf extract can restore the serum levels of AST, ALT, triglycerides, and very low-density lipoprotein [58, 59]. The extract increases the glutathione level, decreases lipid peroxidation [59], restores the SOD/catalase balance [60], and improves histopathology of the liver [61].

The beneficial effects of $M$. nigra on the liver have also been shown in other study designs. In cell culture studies, the fruit juice, hydroalcoholic extract, and polyphenol extract of $M$. nigra showed a significant inhibitory effect on tert-butyl hydroperoxide-induced lipid peroxidation in isolated rat hepatocytes [12]. In D-galactose-induced aging mice, treatment with the leaf extract significantly increased SOD, catalase, and glutathione peroxidase activities and depressed lipid peroxidation in the serum, brain, and liver [62]. In a mouse with lipopolysaccharide-induced sepsis, treatment with the extracts of $M$. nigra leaves and pulp reduced the levels of TNF and increased glutathione content of the liver [63]. In rat model of diethylnitrosamine-induced hepatocellular carcinoma, $M$. nigra fruit extract exhibited a hepatoprotective effect through inhibiting oxidative stress and $\mathrm{Wnt} 4 / \beta$-catenin pathway and prolonged the survival of animals [64].

\section{Potential Effects of $M$. nigra Phytochemicals on the Liver}

It is well known that plant-derived phytochemicals can have beneficial effects on liver function. Some of these phytochemicals include flavonols, flavonolignans (e.g., silymarin), anthocyanins, and terpenoids [65-68]. As mentioned above, $M$. nigra is an applicable source of anthocyanins and flavonols. Potential mechanisms of hepatoprotective effects of $M$. nigra and its phytochemicals are shown in Figure 2. Hepatoprotective activities of flavonols (e.g., quercetin and kaempferol) have been reviewed elsewhere [66], and here we focus on anthocyanins. According to our thorough literature search, reported in Table 2, among $M$. nigra anthocyanins, cyanidin-3-glucoside, delphinidin, and pelargonidin play a major role in the hepatoprotective properties of this plant. In a rat model of diet-induced metabolic syndrome, cyanidin3 -glucoside reversed the increased plasma liver enzymes and enhanced inflammatory cell infiltration in the liver [69]. Protective effects of cyanidin-3-glucoside on alcohol-induced liver fibrosis were found to be mediated through regulating energy homeostasis and the AMP-ac- 
tivated protein kinase/autophagy signaling pathway [70]. Also, cyanidin-3-glucoside could ameliorate $\mathrm{CCl}_{4}$-induced liver injury (decrease of ALT and AST) in mice via increasing the activity of the antioxidant enzymes catalase, SOD, glutathione reductase, and glutathione peroxidase [71]. Also, this anthocyanin reduced hypercholesterolemia in mice by upregulating hepatic cholesterol $7 a$-hydroxylase expression and activating the potential LXRa-CYP7A1-bile acid excretion pathway [72]. In the human hepatocyte cell line, it could enhance mitochondrial membrane potential and ATP production and upregulate the gene expression of peroxisome proliferatoractivated receptor-gamma coactivator 1-alpha, a transcription factor regulating mitochondrial function and biogenesis. Also, the expression of downstream PGC-1a genes, mitochondrial transcription factor $\mathrm{A}$, and nuclear respiratory factor 1 was increased as a result of treatment with cyanidin-3-glucoside [73].

Delphinidin as another major effective anthocyanidin of $M$. nigra is found to attenuate oxidative stress and restore hepatic architectures (by increasing matrix metallothionein I/II and metalloproteinase-9 expression) in $\mathrm{CCl}_{4}$-induced liver fibrosis in mice [74]. Also, this compound reduces triglyceride accumulation in hepatocytes by modulation of lipid metabolic gene expressions [75].

Results of studies in mice with lipopolysaccharide-induced liver damage have shown that pelargonidin attenuates liver failure by inhibiting the toll-like receptor-mediated inflammatory pathway [76]. This anthocyanin ameliorated citrinin-induced oxidative stress in hepatocytes by modulating gene expression of the Keap1/Nrf2 pathway, the major signaling for regulation of cytoprotective responses to electrophilic and oxidative stress [77]. Pelargonidin also activated the aryl hydrocarbon receptorCYP1A1 signaling pathway in hepatocytes [78]. This suggests it may interact with metabolisms of drugs in humans, which should be taken into consideration in future studies.

\section{Toxicology of $M$. nigra}

M. nigra has been used for thousands of years as a fruit and as a medicinal plant in traditional medicine. In the literature, toxicological data about chronic use of this plant are limited. Yilmaz and colleagues [79] used cultured human peripheral lymphocytes to study the potential genotoxic effect of $M$. nigra fruit. Their results demonstrated that the fruit juice had no genotoxic effect but showed protective activity against mitomycin-induced genomic changes.

In the case of $M$. nigra leaves, safety reports are controversial. One study showed that oral administration of aqueous extract of mulberry leaves $(100 \mathrm{mg} / \mathrm{kg}$ twice daily, for 42 days) caused a significant rise in serum ALT and AST activities in both normal and diabetic animals [80]. On the other hand, it has been reported that ethanolic extract of the leaves (up to $1,000 \mathrm{mg} / \mathrm{kg}$, oral, for 28 days) did not induce toxic effects against renal and hepatic tissues [81]. Also, evaluation of the acute toxicity of ethanolic extract of the leaves showed no mortality and no toxicity signs at doses of $2 \mathrm{~g} / \mathrm{kg}$ intraperitoneally and $5 \mathrm{~g} / \mathrm{kg}$ orally in mice [82]. Therefore, according to the evidence reviewed above, it seems that acute and subacute consumption of $M$. nigra is not associated with significant toxic effects. However, the safety of chronic use of $M$. nigra should be investigated by further studies.

\section{Conclusion}

The present review summarized the hepatoprotective effects of $M$. nigra and its phytochemicals. Different parts of this plant particularly the fruit and leaf showed beneficial effects on hepatocytes in cell culture and animal models of liver damages [77]. Oxidative stress and inflammation are in the core of mechanisms of liver damages induced by viruses, drugs, or chemical agents. Although the exact mechanisms of hepatoprotective effects of $M$. nigra are a subject of further studies, the antioxidant and antiinflammatory activities of this plant have been well documented. These activities can be attributed to the presence of considerable amounts of phenolic compounds such as anthocyanins, flavonols, and phenolic acids. The evidence reviewed in this study can help design clinical trials on $M$. nigra in patients with liver disorders and develop a hepatoprotective herbal medicine.

\section{Acknowledgement}

The authors would like to thank the Vice Chancellery for Research and Technology, Mashhad University of Medical Sciences, Mashhad, Iran.

\section{Conflict of Interest Statement}

The authors declare no conflicts of interest. 


\section{Funding Sources}

This research received no external funding.

\section{Author Contributions}

Conceptualization and comprehensive review: A.G.; literature search, preparing tables, and writing original draft: S.H.; both authors have read and approved the submitted version.

\section{References}

1 Mitra V, Metcalf J. Metabolic functions of the liver. Anaesth Intens Care. 2012;13(2):54-5.

2 Angulo P. Nonalcoholic fatty liver disease. N Engl J Med. 2002;346(16):1221-31.

3 Ramachandran A, Jaeschke $H$. Oxidative stress and acute hepatic injury. Curr Opin Toxicol. 2018;7:17-21.

4 Woolbright BL, Jaeschke H. Mechanisms of inflammatory liver injury and drug-induced hepatotoxicity. Curr Pharmacol Rep. 2018; 4(5):346-57.

5 Hassan W, Noreen H, Rehman S, Gul S, Kamal MA, Kamdem JP, et al. Oxidative stress and antioxidant potential of one hundred medicinal plants. Curr Top Med Chem. 2017; 17(12):1336-70.

6 Kazemi S, Shirzad H, Rafieian-Kopaei M. Recent findings in molecular basis of inflammation and anti-inflammatory plants. Curr Pharm Des. 2018;24(14):1551-62.

7 Baby B, Antony P, Vijayan R. Antioxidant and anticancer properties of berries. Crit Rev Food Sci Nutr. 2018;58(15):2491-507.

8 Shukitt-Hale B, Bielinski DF, Lau FC, Willis LM, Carey AN, Joseph JA. The beneficial effects of berries on cognition, motor behaviour and neuronal function in ageing. $\mathrm{Br} \mathrm{J}$ Nutr. 2015;114(10):1542-9.

9 Forbes-Hernández TY, Giampieri F, Gasparrini M, Afrin S, Mazzoni L, Cordero MD, et al. Lipid accumulation in HepG2 cells is attenuated by strawberry extract through AMPK activation. Nutrients. 2017;9(6):621.

10 Giampieri F, Alvarez-Suarez JM, Cordero MD, Gasparrini M, Forbes-Hernandez TY, Afrin S, et al. Strawberry consumption improves aging-associated impairments, mitochondrial biogenesis and functionality through the AMP-activated protein kinase signaling cascade. Food Chem. 2017;234: 464-71.

11 Naderi GA, Asgary S, Sarraf-Zadegan N, Oroojy H, Afshin-Nia F. Antioxidant activity of three extracts of Morus nigra. Phytother Res. 2004;18(5):365-9.

12 Ercisli S, Orhan E. Chemical composition of white (Morus alba), red (Morus rubra) and black (Morus nigra) mulberry fruits. Food Chemistry. 2007;103(4):1380-4.

13 Padilha MM, Vilela FC, Rocha CQ, Dias MJ, Soncini R, dos Santos MH, et al. Antiinflammatory properties of Morus nigra leaves. Phytother Res. 2010;24(10):1496-500.

14 Yi WHWSS, Sen FJZ-YL, Fan TL. An assay on the antiviral activity of mulberry leaf extract. J Sci Sericulture. 2011;5.

15 Harborne JB, Baxter H. The handbook of nat- ural flavonoids. Volume 1 and Volume 2. John Wiley and Sons; 1999.

16 Wadood A, Ghufran M, Jamal SB, Naeem M, Khan A, Ghaffar R. Phytochemical analysis of medicinal plants occurring in local area of Mardan. Biochem Anal Biochem. 2013;2(4):1-4.

17 Pawlowska AM, Oleszek W, Braca A. Qualiquantitative analyses of flavonoids of Morus nigra L. and Morus alba L.(Moraceae) fruits. J Agric Food Chem. 2008;56(9):3377-80.

18 Gundogdu M, Muradoglu F, Sensoy RIG, Yilmaz H. Determination of fruit chemical properties of Morus nigra L., Morus alba L. and Morus rubra L. by HPLC. Scientia Horticulturae. 2011;132:37-41.

19 Radojković MM, Zeković ZP, Vidović SS, Kočar DD, Mašković PZ. Free radical scavenging activity and total phenolic and flavonoid contents of mulberry (Morus spp. L., Moraceae) extracts. Hemijska Indust. 2012;66(4):547-52.

20 Negro C, Aprile A, De Bellis L, Miceli A. Nutraceutical properties of mulberries grown in southern Italy (Apulia). Antioxidants. 2019; 8(7):223.

21 Rodrigues E, Marcelino G, Silva G, Figueiredo P, Garcez W, Corsino J, et al. Nutraceutical and medicinal potential of the Morus species in metabolic dysfunctions. Int J Mol Sci. 2019; 20(2):301.

22 Eyduran SP, Ercisli S, Akin M, Beyhan O, Geçer MK, Eyduran E, et al. Organic acids, sugars, vitamin $\mathrm{C}$, antioxidant capacity, and phenolic compounds in fruits of white (Morus alba L.) and black (Morus nigra L.) mulberry genotypes. J Appl Botany Food Quality. 2015;88:134-8.

23 Sánchez-Salcedo EM, Mena P, GarcíaViguera C, Martínez JJ, Hernández F. Phytochemical evaluation of white (Morus alba L.) and black (Morus nigra L.) mulberry fruits, a starting point for the assessment of their beneficial properties. J Funct Foods. 2015;12: 399-408.

24 Kamiloglu S, Serali O, Unal N, Capanoglu E. Antioxidant activity and polyphenol composition of black mulberry (Morus nigra L.) products. J Berry Res. 2013;3(1):41-51.

25 Kucelova L, Grygorieva O, Ivanišová E, Margarita T, Brindza J. Biological properties of black mulberry-derived food products (Morus nigra L.). J. Berry Res. 2016;6(3):333-43.

26 Zeni ALB, Moreira TD, Dalmagro AP, Camargo A, Bini LA, Simionatto EL, et al. Evaluation of phenolic compounds and lipid-lowering effect of Morus nigra leaves extract. An Acad Bras Cienc. 2017 Oct-Dec;89(4):2805-15.

27 Pérez-Gregorio MR, Regueiro J, AlonsoGonzález E, Pastrana-Castro LM, Simal-
Gándara J. Influence of alcoholic fermentation process on antioxidant activity and phenolic levels from mulberries (Morus nigra L.). LWTFood Sci Technol. 2011;44(8):1793-801.

28 Arfan M, Khan R, Rybarczyk A, Amarowicz R. Antioxidant activity of mulberry fruit extracts. Int J Mol Sci. 2012;13(2):2472-80.

29 Roussos PA, Denaxa N-K, Ntanos E, Tsafouros A, Mavrikou S, Kintzios S. Organoleptic, nutritional and anti-carcinogenic characteristics of the fruit and rooting performance of cuttings of black mulberry (Morus nigra L.) genotypes. J Berry Res. 2020(Preprint):1-17.

30 Hollman PCH. Absorption, bioavailability, and metabolism of flavonoids. Pharm Biol. 2004;42(Suppl 1):74-83.

31 Manach C, Donovan JL. Pharmacokinetics and metabolism of dietary flavonoids in humans. Free Radic Res. 2004;38(8):771-85.

32 He J, Feng Y, Ouyang H-Z, Yu B, Chang Y-X, Pan G-x, et al. A sensitive LC-MS/MS method for simultaneous determination of six flavonoids in rat plasma: application to a pharmacokinetic study of total flavonoids from mulberry leaves. J Pharm Biomed Anal. 2013;84:189-95.

33 Jeon J, Ma S-Y, Choi DS, Jang B-S, Kang JA, Nam YR, et al. Radiosynthesis of 123I-labeled hesperetin for biodistribution study of orally administered hesperetin. J Radioanal Nucl Chem. 2015;306(2):437-43.

34 Choi MH, Rho JK, Kang JA, Shim HE, Nam YR, Yoon S, et al. Efficient radiolabeling of rutin with $125 \mathrm{I}$ and biodistribution study of radiolabeled rutin. J Radioanal Nucl Chem. 2016;308(2):477-83.

35 Fang J. Bioavailability of anthocyanins. Drug Metab Rev. 2014;46(4):508-20.

36 Passamonti S, Vrhovsek U, Mattivi F. The interaction of anthocyanins with bilitranslocase. Biochem Biophys Res Commun. 2002; 296(3):631-6.

37 Marques C, Fernandes I, Norberto S, Sá C, Teixeira D, de Freitas V, et al. Pharmacokinetics of blackberry anthocyanins consumed with or without ethanol: a randomized and crossover trial. Mol Nutr Food Res. 2016; 60(11):2319-30.

38 Cahyana Y, Gordon MH, Gibson TM. Urinary excretion of anthocyanins following consumption of strawberry and red grape juice. Int J Vitam Nutr Res. 2019;89(1-2):29-36.

$39 \mathrm{Gu}$ X, Manautou JE. Molecular mechanisms underlying chemical liver injury. Expert Rev Mol Med. 2012;14:e4.

$40 \mathrm{Wu}$ J, Lin S, Wan B, Velani B, Zhu Y. Pyroptosis in liver disease: new insights into disease mechanisms. Aging Dis. 2019;10(5):1094-108. 
41 Mao L, Zhao T, Song Y, Lin L, Fan X, Cui B, et al. The emerging role of ferroptosis in noncancer liver diseases: hype or increasing hope? Cell Death Dis. 2020;11(7):518.

42 Radu-Ionita F, Bontas E, Tintoiu IC. Hepatocellular death: apoptosis, autophagy, necrosis and necroptosis. liver diseases. Springer; 2020. p. 37-52.

43 Friedman SL, Neuschwander-Tetri BA, Rinella M, Sanyal AJ. Mechanisms of NAFLD development and therapeutic strategies. Nat Med. 2018;24(7):908-22.

44 Zeng L, Tang WJ, Yin JJ, Zhou BJ. Signal transductions and nonalcoholic fatty liver: a minireview. Int J Clin Exp Med. 2014;7(7):1624-31.

45 García-Ruiz C, Fernández-Checa JC. Mitochondrial oxidative stress and antioxidants balance in fatty liver disease. Hepatol Commun. 2018;2(12):1425-39.

46 Tarantino G, Citro V, Capone D. Nonalcoholic fatty liver disease: a challenge from mechanisms to therapy. J Clin Med. 2020;9(1):15.

47 Deniz G, Laloglu E, Koc K, Nadaroglu H, Geyikoglu F. The effect of black mulberry (Morus nigra) extract on carbon tetrachloride-induced liver damage. Arch Biol Sci Belgra. 2018;70(2):371-8.

48 Mnaa S, Aniess W, Olwy Y, Shaker E. Antioxidant activity of white (Morus alba L.) and black (Morus nigra L.) berries against CCl4 hepatotoxic agent. Adv Tech Biol Med. 2014:1-7.

49 Youssef FS, Labib RM, Eldahshan OA, Singab ANB. Synergistic hepatoprotective and antioxidant effect of artichoke, fig, mulberry herbal mixture on HepG2 cells and their metabolic profiling using NMR coupled with chemometrics. Chem Biodivers. 2017;14(12):e1700206.

50 Hinson JA, Roberts DW, James LP. Mechanisms of acetaminophen-induced liver necrosis. Handb Exp Pharmacol. 2010(196):369-405.

51 Mallhi TH, Qadir MI, Khan YH. Determination of phytoconstituents of n-hexane extract of leaves of Morus nigra and evaluation of their effects on biochemical and histopathological parameters in paracetamol intoxicated mice liver. Braz J Pharm Sci. 2018;54(3):e18101.

52 Mallhi TH, Qadir MI, Khan YH, Ali M. Hepatoprotective activity of aqueous methanolic extract of Morus nigra against paracetamolinduced hepatotoxicity in mice. Bangladesh J Pharmacol. 2014;9(1):60-6.

53 Conway R, Carey JJ. Risk of liver disease in methotrexate treated patients. World J Hepatol. 2017;9(26):1092-100.

54 Tag HM. Hepatoprotective effect of mulberry (Morus nigra) leaves extract against methotrexate induced hepatotoxicity in male albino rat. BMC Complement Altern Med. 2015;15(1):252.

55 Song H, Lai J, Tang Q, Zheng X. Mulberry ethanol extract attenuates hepatic steatosis and insulin resistance in high-fat diet-fed mice. Nutr Res. 2016;36(7):710-8.

56 Jiang Y, Dai M, Nie WJ, Yang XR, Zeng XC. Effects of the ethanol extract of black mulberry (Morus nigra L.) fruit on experimental atherosclerosis in rats. J Ethnopharmacol. 2017; 200:228-35.
57 Yang DK, Jo DG. Mulberry fruit extract ameliorates nonalcoholic fatty liver disease (NAFLD) through inhibition of mitochondrial oxidative stress in rats. Evid Based Complement Alternat Med. 2018;2018:8165716.

58 Júnior IId. S, Barbosa Hd. M, Carvalho DCR, Barros Rd. A, Albuquerque FP, Da Silva DHA, et al. Brazilian Morus nigra attenuated hyperglycemia, dyslipidemia, and prooxidant status in alloxan-induced diabetic rats. Sci World J. 2017;2017:5275813.

59 Hago S, Mahrous EA, Moawad M, Abdel-Wahab S, Abdel-Sattar E. Evaluation of antidiabetic activity of Morus nigra L. and Bauhinia variegata L. leaves as Egyptian remedies used for the treatment of diabetes. Nat Prod Res. 2021;35(5):829-35.

60 Araujo CM, Lúcio KP, Silva ME, Isoldi MC, de Souza GH, Brandão GC, et al. Morus nigra leaf extract improves glycemic response and redox profile in the liver of diabetic rats. Food Funct. 2015;6(11):3490-9.

61 Hassanalilou T, Payahoo L, Shahabi P, Abbasi MM, Jafar-abadi MA, Bishak YK, et al. The protective effects of Morus nigra L. leaves on the kidney function tests and histological structures in streptozotocin-induced diabetic rats. Biomed Res. 2017;28(14):6113-8.

62 Turgut NH, Mert DG, Kara H, Egilmez HR, Arslanbas E, Tepe B, et al. Effect of black mulberry (Morus nigra) extract treatment on cognitive impairment and oxidative stress status of d-galactose-induced aging mice. Pharm Biol. 2016;54(6):1052-64.

63 de Pádua Lúcio K, Rabelo ACS, Araújo CM, Brandão GC, de Souza GHB, da Silva RG, et al. Anti-inflammatory and antioxidant properties of black mulberry (Morus nigra L.) in a model of LPS-induced sepsis. Oxid Med Cell Longev. 2018;2018:5048031.

64 Hooshmand Sara, Mahdinezhad Mohammad Reza, Taraz Jamshidi Shirin, Soukhtanloo Mohammad, Mirzavi Farshad, Iranshahi Mehrdad, et al. Morus nigra L. extract prolongs survival of rats with hepatocellular carcinoma. Phytother Res. 2021 [Online ahead of print].

65 Thoppil RJ, Bishayee A. Terpenoids as potential chemopreventive and therapeutic agents in liver cancer. World J Hepatol. 2011;3(9):228-49.

66 Valenti L, Riso P, Mazzocchi A, Porrini M, Fargion S, Agostoni C. Dietary anthocyanins as nutritional therapy for nonalcoholic fatty liver disease. Oxid Med Cell Longev. 2013; 2013:145421.

67 Vargas-Mendoza N, Madrigal-Santillán E, Morales-González A, Esquivel-Soto J, Esquivel-Chirino C, García-Luna Y González-Rubio $\mathrm{M}$, et al. Hepatoprotective effect of silymarin. World J Hepatol. 2014;6(3):144-9.

68 Miltonprabu S, Tomczyk M, SkalickaWoźniak K, Rastrelli L, Daglia M, Nabavi SF, et al. Hepatoprotective effect of quercetin: From chemistry to medicine. Food Chem Toxicol. 2017;108(Pt B):365-74.

69 Bhaswant M, Fanning K, Netzel M, Mathai ML, Panchal SK, Brown L. Cyanidin 3-glucoside improves diet-induced metabolic syndrome in rats. Pharmacol Res. 2015;102:208-17.

70 Wan T, Wang S, Ye M, Ling W, Yang L. Cyanidin-3-O- $\beta$-glucoside protects against liver fibrosis induced by alcohol via regulating energy homeostasis and AMPK/autophagy signaling pathway. J Funct Foods. 2017;37: $16-24$.

71 Cho BO, Lee CW, So Y, Jin CH, Kang SY, Kim DS, et al. Cyanidin-3-glucoside ameliorates CCl4-induced liver injury in mice. Food Sci Biotechnol. 2014;23(4):1313-9.

72 Wang D, Xia M, Gao S, Li D, Zhang Y, Jin T, et al. Cyanidin-3-O- $\beta$-glucoside upregulates hepatic cholesterol $7 a$-hydroxylase expression and reduces hypercholesterolemia in mice. Mol Nutr Food Res. 2012;56(4):610-21.

73 Mogalli R, Matsukawa T, Shimomura O, Isoda H, Ohkohchi N. Cyanidin-3-glucoside enhances mitochondrial function and biogenesis in a human hepatocyte cell line. Cytotechnology. 2018;70(6):1519-28.

74 Domitrović R, Jakovac H. Antifibrotic activity of anthocyanidin delphinidin in carbon tetrachloride-induced hepatotoxicity in mice. Toxicology. 2010;272(1-3):1-10.

75 Parra-Vargas M, Sandoval-Rodriguez A, Rodriguez-Echevarria R, Dominguez-Rosales J, Santos-Garcia A, Armendariz-Borunda J. Delphinidin ameliorates hepatic triglyceride accumulation in human HepG2 cells, but not in diet-induced obese mice. Nutrients. 2018; 10(8): 1060

76 Lee W, Lee Y, Kim J, Bae J-S. Protective effects of pelargonidin on lipopolysaccharide-induced hepatic failure. Natural Product Communications. 2018;13(1):1934578X1801300.

77 Sharath Babu GR, Anand T, Ilaiyaraja N, Khanum F, Gopalan N. Pelargonidin modulates Keap1/Nrf2 pathway gene expression and ameliorates citrinin-induced oxidative stress in HepG2 cells. Front Pharmacol. 2017;8:868.

78 Kamenickova A, Anzenbacherova E, Pavek P, Soshilov AA, Denison MS, Anzenbacher P, et al. Pelargonidin activates the AhR and induces CYP1A1 in primary human hepatocytes and human cancer cell lines HepG2 and LS174T. Toxicol Lett. 2013;218(3):253-9.

79 Yilmaz S, Uçar A, Göktaş B. Genotoxic and genoprotective potential of black mulberry (Morus nigra) fruit. An Acad Bras Cienc. 2019;91(4):e20190337.

80 Hemati A, Jalali M, Rashidi I, Kalantar HT. Impact of aqueous extract of black mulberry (morus nigra) on liver and kidney funcion of diabetic mice. Jundishapur J Nat Pharm Prod. 2010;5(1):18-25.

81 Figueredo KC, Guex CG, Reginato FZ, Haas da Silva AR, Cassanego GB, Lhamas CL, et al. Safety assessment of Morus nigra L. leaves: acute and subacute oral toxicity studies in $\mathrm{Wi}$ star rats. J Ethnopharmacol. 2018;224:290-6.

82 Quintans Júnior LJ, de Sá PG, Oliveira RA Neves LF, Silva FS, Araújo ECC, et al. Evaluation of hypoglycemic potential and pre-clinical toxicology of Morus nigra L.(Moraceae). Latin Am J Pharm. 2011;30(1):96-100. 